\title{
Hybrid Prosthetic Treatment of the Edentulous Mandible with Two or Four Implants - A Literature Review
}

\author{
Ketabi $\mathrm{AR}^{1^{*}}$, Bornemann $\mathrm{G}^{2}$, Ketabi $\mathrm{S}^{3}$ and Lauer $\mathrm{HC}^{4}$ \\ ${ }^{1}$ Private Practice, Specialist for Implantology, Stuttgart, Germany \\ ${ }^{2}$ Private Practice, Idstein, Germany \\ ${ }^{3}$ Maxillofacial Surgery, Katharinenhospital Stuttgart, Germany \\ ${ }^{4}$ Department of Prosthetic Dentistry, University of Frankfurt, Germany
}

*Corresponding author: Dr. Ali-Reza Ketabi, Private Practice, Specialist for Implantology, Epplestr. 29 aD-70597 Stuttgart (Degerloch), Germany, Tel: 0049-711-4400952; Fax: 0049-711-4400406; E-mail: ketabi@vasel-ketabi.de

Rec date: Jun 18, 2014, Acc date: Aug 21, 2014, Pub date: Aug 23, 2014

Copyright: (C) 2014 Ketabi AR, et al. This is an open-access article distributed under the terms of the Creative Commons Attribution License, which permits unrestricted use, distribution, and reproduction in any medium, provided the original author and source are credited

\begin{abstract}
Treatment of an edentulous mandible is an important standard area of indication for implants. The aim of the present study was to discuss various aspects of this very important topic using a literature research and possibly derive a recommendation for hybrid prosthetic treatment of the edentulous mandible.

Though evaluation of the literature produced a large number of publications with case histories and survival rates, there were only a few prospective randomised clinical studies that compared different treatment concepts in the edentulous mandible to allow an evidence-based statement.

Despite all the limitations imposed on the interpretation of the study, the following statements could be made with regard to implant-supported dentures in the edentulous mandible:

Two implants represent the easiest, most inexpensive treatment and are adequate for stabilizing a denture in an edentulous mandible. This type of restoration is easy to maintain for the patient with regard to oral hygiene and surgery stress is reduced to a minimum. The disadvantages of this treatment are increased mobility and instability of the denture in the dorsal region.

Apart from increased intraoral comfort, the advantages of treatment using four implants include the stable fit of the denture and the option of immediate restoration.
\end{abstract}

Keywords: Complete hybrid prosthetic overdentures; Edentulous mandible; Full-arche construction; Hybrid prosthetic; Peri-implant bone loss

\section{Introduction}

Endosseous implants are being increasingly used for the retention of restorations in recent years, particularly in the edentulous mandible. Various treatment options are available for rehabilitation of the edentulous mandible using implants and overdentures. Relatively simple implantological measures can be used for rehabilitation of masticatory and phonetic functions by stabilizing the position of the removable restoration.

The number of implants to be placed for supporting a removable full denture, however, is controversial. Though the German Society for Oral and Maxillofacial Medicine (DGZMK) recommends support on four implants, other authors regard two implants as adequate.

The aim of this study was, therefore, to discuss different aspects of the problem using a literature research and possibly advice a recommendation for treating the edentulous mandible with a hybridprosthetic overdenture.

\section{Problem}

In the majority of cases patients are treated with a full denture following tooth loss [1]. Due to altered functional conditions the mandible can undergo severe vertical atrophy to the extent that a conventional full denture increasingly loses stability and retention. The denture begins to rock and causes the patient increasing problems during mastication and speaking [2,3]. Electrognathographic measurements indicate that more stable and more efficient masticatory movements are possible with implant-retained full dentures in the mandible compared with conventional full prosthetic dentures and that an objective improvement in masticatory and phonetic functions can be achieved [4,5].

Apart from functional aspects, psychological factors should also be taken into consideration when fitting full dentures. Patients often feel that the loss of teeth is a sign of aging and accompanying loss of attractiveness. An implant-retained restoration can increase the feeling of wellbeing and quality of life of the patient [6-9].

The decision about the type and extent of the restoration must be made depending on numerous factors: general health of the often older patients, willingness and ability to cooperate, morphological conditions as well as aesthetic and functional aspects. Implant- 
supported dentures are now regarded as standard treatment. Support is usually provided by two or four interforaminal implants. The connection between the denture and implants is provided by different types of abutment. The connection can be produced using bars, ball attachments, magnets or telescopes. A fixed restoration, which has to be supported on a greater number of implants, can be used as an alternative to removable dentures $[10,11]$.

Numerous experiments and clinical observations indicate that it is possible to achieve long-term osseointegration of implants despite transgingival emergence [12-19]. And that it can slow down atrophy of the alveolar bone in comparison with conventional treatment [20-22].

Following implant treatment there may be signs of resorption of the peri-implant bone tissue, which can generally be attributed to surgical trauma, biomechanical factors and bacterial infections. Progressive bone loss leads to a lack of anchorage for the implant and therefore a lack of retention. This can result in loosening and consequently implant failure [12,23-26].

The peri-implant bone situation is therefore an important criterion for implant prognosis. In addition to clinical diagnoses, radiological documentation of the peri-implant bone condition plays an important role in the follow-up examination [27-29].

There is a commonly held assumption that support of the denture by 4 implants causes less peri-implant bone resorption than support on two implants. This can only be based on clinical experience, however, as despite the large number of publications on implant placement in the edentulous mandible there have not yet been a longterm studies to prove this theory scientifically.

\section{Literature Research - Methods and Sources}

An Internet literature research was completed for the present study in Medline ("http://www.ncbi.nlm.nih.gov"), the largest medical database in the world. The research included all publications up to July 2014.

First, an initial overview was acquired in the form of 2295 bibliographic references using the search keywords "dental implant in edentulous mandible" in PubMed. A more specific search was then initiated using "hybrid prosthetic implant-supported in edentulous mandible", this generated only nine bibliographic references. In the search of the abstracts there were only references to "related Citations". The search was therefore widened as follows: "see all related Citations". This search found 685 further publications. Other references from subject-specific articles were also searched. Only publications in German and English were considered, which enabled evaluation of hybrid prosthetic treatment of the edentulous mandible using two or four implants. The articles were checked in a full-text search for the following inclusion criteria: a minimum study period of one year, data relating to bone resorption or implant survival rate, comparable study design. Case reports and review articles as well as one epidemiology study were not included in the study due to a lack of relevance for this investigation. The results of this publication were analysed with regard to study period, number of patients, number of implants and study design to achieve a final statement.

\section{Results}

The literature research produced 694 entries. In the preselection described 25 observational studies, five studies on the influence of opposing jaw treatment and four studies (Table 1) with comparable characteristics were found, which evaluated hybrid prosthetic treatment of the edentulous mandible with two or four implants.

\begin{tabular}{|l|l|l|l|l|}
\hline Study & $\begin{array}{l}\text { Study } \\
\text { design }\end{array}$ & $\begin{array}{l}\text { Study } \\
\text { period } \\
\text { of } \\
\text { patients } \\
\text { (n) }\end{array}$ & $\begin{array}{l}\text { Number of Implants } \\
\text { (patients) / superstructure }\end{array}$ \\
\hline $\begin{array}{l}\text { Batenburg } \\
\text { et al. [34] }\end{array}$ & prospective & 1 Year & $\begin{array}{l}60 \\
\text { patients }\end{array}$ & $\begin{array}{l}2 \text { Groups with 30 patients, 2 } \\
\text { vs. Implants / } \\
\text { bar superstructure }\end{array}$ \\
\hline $\begin{array}{l}\text { Meijer et } \\
\text { al. [39] }\end{array}$ & $\begin{array}{l}\text { finite } \\
\text { element } \\
\text { study }\end{array}$ & - & - & $\begin{array}{l}2 \text { vs. 4 Implants / } \\
\text { bar superstructure vs. free- } \\
\text { standing implants }\end{array}$ \\
\hline $\begin{array}{l}\text { Visser et } \\
\text { al. [61] }\end{array}$ & prospective & 5 Years & $\begin{array}{l}60 \\
\text { patients }\end{array}$ & $\begin{array}{l}2 \text { Groups with 30 Patients, 2 } \\
\text { vs. } 4 \text { Implants / } \\
\text { bar superstructure }\end{array}$ \\
\hline $\begin{array}{l}\text { Wismeijer } \\
\text { et al. [62] }\end{array}$ & prospective & 19 & $\begin{array}{l}110 \\
\text { patients }\end{array}$ & $\begin{array}{l}3 \text { Groups with 37/37/36 } \\
\text { Patients, 2 vs. 4 Implants / } \\
2 \text { Implants with / without and } \\
4 \text { Implants with bar sup }\end{array}$ \\
\hline
\end{tabular}

Table 1: Studies with comparison of 2 versus 4 implants in the edentulous mandible

\section{Studies with Data on the Survival Rates of Implant-Retained Verdentures for Treatment of the Edentulous Mandible}

Survival rates of $98.8 \%, 96 \%$ and $97.4 \%$ [30-32] were given in three retrospective studies with an observation period of five, six and 10 years. A comparison of the number of implants or attachments was not completed. The studies reported a high degree of patient satisfaction and indicated that optimal oral hygiene is required for successful prognosis. Regular check-ups are also indispensible for early diagnosis of peri-implant disorders.

In a prospective study Bakke et al. established that there was a considerable improvement in masticatory function, the bite force increased and the length of masticatory cycles reduced after patients were treated using implant-supported overdentures [33].

In a prospective study Batenburg et al. investigated the peri-implant tissue following placement of three different implant systems. Two Brånemark, two IMZ or two ITI implants were each placed in 30 patients and fitted with a bar-supported full denture. Intraoral radiographs were prepared using the long-cone technique postoperatively as well six and 12 months after implant placement. In the Brånemark and IMZ group there was significant bone loss after 12 months (Brånemark $0.34 \mathrm{~mm}$; IMZ $0.53 \mathrm{~mm}$ ); in the ITI group bone loss after 12 months was not significant (ITI $0.19 \mathrm{~mm}$ ). There were therefore no clinically relevant differences between the three implant systems during an observation period of 12 months. The Batenburg working group concluded that two interforaminal implants (Brånemark, IMZ, ITI) with a bar superstructure provide a suitable base for a mandibular full denture [34].

In an in vitro study on mandibular models with four implants Besimo et al. investigated the force transference to implants in relation 
to the type of mesostructure. The results indicated more favourable force transference with telescopes than with restorations using bars as the primary connector. The telescope crown restorations also had a more stable fit [35].

In a prospective study Cune et al. investigated the survival rate of two implants, which were fitted with ball attachments and an overdenture after a healing period of three months. The survival rate after one year was $93.9 \%$ [36].

In a publication Gomez-Roman et al. presented a summary of the results of a retrospective study on retention of dentures in the edentulous mandible with three implant systems (Bonefit, IMZ, TPS). A total of 53 patients with four implants each (number of implants 212) and 105 patients with two interforaminal implants each (number of implants 210) were investigated over a period of up to 10 years after prosthetic treatment. In the period between implant placement and prosthetic treatment the coronal bone defect increased on average by $0.5 \mathrm{~mm}$ and by $0.5-1 \mathrm{~mm}$ at the check-up after one year. On average there was no further resorption at the check-up after two and three years. A comparison of two versus four implants was not completed [25].

Heckmann et al. reported on the changes of peri-implant hard and soft tissue in patients with two interforaminal implants and conical telescopes as attachments. After an observation period of 10 years there was an increased plaque index, though this did not affect the sulcus fluid flow rate or bleeding index. The periotest values were therefore stable; the mean of the bone resorption (DIB/ distance implant bone) was $3.19 \mathrm{~mm}$. There was no correlation found between the DIB and the clinical parameters. The authors concluded from this that these parameters may be useful in clinical examinations as indicators for bone resorption [37].

In a prospective study by Makkonen et al. the survival rates of six implants with a screw-retained full restoration and four implants with a bar and overdenture were investigated. The cumulative survival rate for the two groups after five years was $98.7 \%$ [38].

In a prospective multicentre study Meijer et al. observed the clinical and radiological parameters following placement of three different implant systems. In the first group two IMZ implants were placed, two Brånemark implants were placed in patients in the second group and transmandibular implants (TMI) were placed in patients in the third group. After six years the TMI group had a significantly higher plaque index. There were no significant differences with regard to the other clinical and radiological parameters. The survival rates in the IMZ and Brånemark groups were comparable with $97.5 \%$ and $97.1 \%$, while the rate in the TMI group was only $72 \%$. The Meijer working group concluded that restoration with two IMZ or two Brånemark implants was a suitable treatment for the edentulous mandible [39]. In another retrospective study Meijer et al. investigated the influence of the patient's age on the success rate of an implant prosthetic restoration in the edentulous mandible. Both the younger age group with an average age of 46 years and the older age group with an average age of 68 years exhibited no significant differences after three years with regard to the clinical parameters (plaque index, bleeding index, gingival index). The peri-implant bone resorption in the younger age group was $1.2 \mathrm{~mm}$ during this period and in the older age group it was only $0.8 \mathrm{~mm}$. Successful mandibular implant treatment is possible both with younger and older patients [40].

A retrospective study by Oetterli et al. investigated the influence of the retentive units for overdentures on the peri-implant bone in patients who were treated with two interforaminal implants and a bar or two ball attachments. After five years there was no evidence of any influence on the atrophy of the bone [41].

In a randomized prospective study Romeo et al. were unable to establish any statistically significant differences between immediate loading and delayed loading involving four implants with a bar superstructure in the edentulous mandible [42].

A prospective study by Romeo et al. included investigation of the long-term survival rate of overdentures on two-four implants with a bar superstructure. There was a survival rate of $95.7 \%$ after an observation period of seven years. There was not further subdivision of the group into two versus four implants [43].

Walton et al. carried out a randomized prospective study with two implants and either ball attachments or bars as retentive elements to the overdenture. Though fabrication time, treatment time and fabrication costs for both groups were comparable, there were considerable differences in the amount of repairs required after an observation period of one year. In the case of restorations with ball attachments $84 \%$ of patients required a minimum of one repair and in the case of patients with a bar restoration it was only $20 \%$ [44].

In a clinical study Stocker and Wismeijer presented the outcomes of the immediate loading of two bar-splinted implants retaining a mandibular overdenture. The cumulative implant success rate at 1 year was $94 \%$. The authors concluded that two interconnected implants can be successfully loaded by a mandibular overdenture at the same day of implant placement with a high survival rate of the implants [45].

In a prospective study Liao et al. reported in their prospective study the success rate of immediate loading of two freestanding implants retaining a mandibular overdenture. Ten adults underwent treatment that included a maxillary removable complete denture opposing a mandibular removable overdenture retained by two freestanding implants. In this 1-year pilot prospective study, two immediately loaded unsplinted mandibular symphyseal implants retaining an overdenture resulted in favorable implant success and peri-implant tissue response [46].

Turkyilmaz et al. evaluated treatment outcomes of mandibular overdentures retained by two unsplinted, early-loaded implants and compared these results with those for delayed-loaded implants. In the test group, the overdenture was loaded 1 week after surgery and in the control group, the overdenture was loaded 3 months after surgery. The results of this clinical trial showed that there is no significant difference in the clinical and radiographic outcomes of patients treated with mandibular overdentures supported by two implants that are either early or delayed loaded [47].

Krennmair et al. evaluated implant success, peri-implant conditions, and prosthodontic maintenance requirements and compared for mandibular overdentures supported by two implants and retained with ball or resilient telescopic crown attachments during a 5-year period. Implant success, peri-implant conditions, and subjective patient satisfaction scores did not differ between the two retention modalities used. However, during the 5-year observation period, significantly more postinsertion complications/interventions for maintenance purposes were registered in the ball group than in the telescopic crown group. The authors concluded that both ball attachments and resilient telescopic crowns on isolated implants in the 
atrophic mandible are viable treatment options for implant-supported overdentures [48].

In a finite element study Dashti et al. investigated the effects of two attachment types (bar and clip system) on the basis of the stresses introduced to the mandibular posterior residual ridge by an overdenture retained by two implants. Within the limitations of this study, the ball system was shown to introduce a lower amount of stress to the posterior mandibular residual ridge compared to a bar and clip system [49].

In a prospective cohort study Scepanovic et al. observed the overdenture success, implant success and biological and prosthetic complications after the first year of service. Thirty patients received mandibular conventional complete dentures that were subsequently retained by 4 immediately loaded mini dental implants placed in the interforaminal region. The authors resumed that mini dental implant retained overdentures can be a successful therapeutic procedure for treating mandibular edentulism that improves quality of life, patient satisfaction and chewing ability in patients wearing maxillary dentures. Longer follow-ups are needed to validate this therapy in the medium and long-term [50].

Eccellente et al. evaluated patients with a mandibular overdenture supported by the Ankylos SynCone system. The treatment method was based on immediate loading of four interforaminal implants without the use of a bar retainer. The denture was placed on and retained by prefabricated conical crowns that were inserted into the existing denture base by direct intraoral polymerization. The cumulative implant survival rate was $98.7 \%$, while the prosthesis survival rate was $100 \%$ after a total observation of 30.3 months. The authors summarize the conical crowns concept presented here resulted in stable complete denture retention, reduced the denture base, and improved oral hygiene [51].

Heschl et al. performed a prospective study to evaluate the outcomes of $\mathrm{XiVE}^{\oplus} \mathrm{S}$ plus implants following conventional restoration with bar structures and overdentures in the edentulous mandible. Dolder bars to restore oral implants in the edentulous mandible appear to offer a high rate of implant survival, good stability of the peri-implant tissue, and a low rate of prosthetic complications [52].

In a retrospective practice-based study Frisch et al. evaluated the long-term clinical outcome of implant-supported over-dentures (IODs) retained by double crowns supported by 2-6 implants. The mean follow-up period was $14.1 \pm 2.8$ years. One implant failed after 4.9 years (cumulative-survivalrate: 98.9\%). Seven implants in two patients showed peri-implantitis (prevalence: patient-based $=9.1 \%$ / implant-based $=8 \%$ ). Five dentures were renewed (prosthetic-survival rate $77.3 \%$ ) The authors concluded that IODs retained with double crowns offer predictable long-term performance with a limited incidence of biological and technical complications [53].

\section{Studies with Data on the Influence of a Restoration in the Opposing Jaw on the Survival Rate of Implants in the Edentulous Mandible}

Naert et al. established after a period of seven years following implant exposure that patients with an implant-supported restoration in the opposing jaw had significantly greater peri-implant resorption than patients with a natural dentition, periodontal-supported or mucosa-supported restoration in the opposing jaw [54].
Over a period of five years Eliasson et al. observed a total of 119 patients who had each been treated with a fixed restoration on 4 implants. There was a higher incidence of acrylic teeth fracturing in the mandibular denture in patients with implant-supported restorations in the opposing jaw. There was, however, no significant difference in bone loss with regard to the opposing jaw restoration [55].

Carlsson et al. investigated the influence of the opposing jaw restoration in a study involving 47 patients over a maximum period of 15 years: thirteen patients were fitted with an implant-supported restoration in the opposing jaw and 34 patients were treated with a standard full denture. The mean bone loss after 10 years was less than $1 \mathrm{~mm}$; there was, however, no significant difference [56].

In their study Narhi et al. observed the changes of the edentulous maxilla following implant prosthetic treatment of the edentulous mandible. Significant bone resorption rates were established in the maxilla after six years; these were, however, independent of the type of mandibular restoration [57].

In another study Elsyad et al. investigated the clinical and radiographic changes in the edentulous maxilla in patients with either ball (group 1) or telescopic (group 2) attachments of implantretained mandibular overdentures. After 4 years of denture-wearing, maxillary denture retention was significantly higher in group 1 than in group 2, while occurrence of flabby ridges was significantly higher in group 2 than in group 1. The change in of the anterior region of the maxilla was significantly higher than the change in the posterior region in both groups. Group 2 showed significant anterior residual ridge resorption compared to group 1. The authors concluded that telescopic attachments for implant-retained mandibular overdentures are associated with increased maxillary ridge resorption and flabbiness, and decreased maxillary denture retention when compared to ball attachments [58].

\section{Studies with Comparison of Two versus Four Implants in the Edentulous Mandible}

Batenburg et al. studied the influence of the number of implants in mandibular full dentures on the peri-implant tissue over an observation period of 12 months. In these prospective study 30 patients each received two IMZ implants and another 30 patients each received four IMZ implants. The peri-implant bone loss was determined radiologically from intraoral images using the long-cone technique. As in the previously cited study, bone loss was defined by the distance between the alveolar bone and initial bone-implant contact. Analysis indicated that after 12 months there was no significant difference between the two groups with regard to bone change. Batenburg et al. concluded from this analysis that no more than two implants are required for stabilizing a mandibular full denture [59].

In a finite element study Meijer et al. investigated the differences in load distribution in the peri-implant bone with support on two and four implants in the edentulous mandible. The finite element method enables the behaviour patterns and concentrations of compressive loads and stresses within the implant and surrounding tissue to be calculated using a computer programme. The study involved comparison of models with two and four implants as well as with a bar superstructure and free-standing implants. Surprisingly it was established that a higher number of implants did not automatically reduce loading of the peri-implant bone. In the case of free-standing 
implants there was a higher compressive load with four implants than with two implants. In implants connected by a bar the greatest compressive load was exhibited by the two-implant model and the highest tensile load was exhibited by the four-implant model. There was no marked reduction in loading with four implants compared with two implants in any of the models examined [60].

In a prospective comparative study Visser et al. investigated the treatment success of hybrid dentures in the mandible over a period of five years in relation to the number of implants. In group one the patients received two IMZ implants each and in group two the patients received four implants each. There were no significant differences with regard to the clinical and radiological parameters [61].

The Wismeijer working group from the Netherlands investigated 110 patients with edentulous mandibles who were treated with three different types of implant restorations (ITI implants):

a) two ball attachment implants, b) two implants with a bar, c) four implants with a bar Radiological and clinical findings (bleeding index, plaque index, probe depth) were recorded over a period of 19 months from the time of implant placement. Six implants (2\%) failed during osseointegration; there were no further failures. Radiological analysis indicated a bone loss of (+/-0.26) after 19 months for all implants. In the cases with four implants and bar attachment there was statistically significant greater bone resorption around the central two implants $(2.1 \mathrm{~mm}+/-0.31 \mathrm{~mm})$ compared with the lateral implants $(1.4 \mathrm{~mm}+/-$ $0.25 \mathrm{~mm})$ [62].

The German Maxillofacial Surgery Association (DGZMK) recommends supporting removable restorations in the edentulous mandible on four implants. This type of restoration ensures greater stability of the denture with less bone resorption in the distal region of the alveolar ridge than only two-implant support [63].

\section{Discussion}

Numerous working groups have described, compared and analysed the different prosthetic treatment options involving implantsupported dentures in the mandible. There is, however, disagreement on the number of implants required and the correct type of prosthetic restoration for specific treatment situations. The statements of the majority of publications are based on clinical experience and case histories. Scientific, evidence-based analysis of suitable restorations is still in its infancy. Only a few randomized prospective studies with longer observation periods have been carried out to date. There is comparison of implant-supported overdentures involving two versus four implants in only four studies [59-62]. There have been just as few studies that have investigated the influence of the opposing jaw on the treatment success of the mandible with implants.

In general, it should be noted that when comparing the studies of different authors there is considerable variation in the methods used. The number of implants investigated and the observation period as well as the clinical investigation parameters differed greatly. In the majority of studies changes in the peri-implant bone tissue were considered an important comparative criterion for the success of a treatment. Depending on the study, however, different references points were given $[24,34,56,55,59]$. This made comparative interpretation much more difficult [64-67].

Correlation between insufficient oral hygiene and progression of resorption was observed both in clinical and animal experiment studies. Accumulation of bacteria caused inflammation of the peri- implant mucosa and consequently induced resorption of the periimplant bone. Occlusal loading was also a decisive factor. Overloading of the implant can result in increased bone resorption and even failure of osseointegration $[26,68]$.

\section{Comparison of Bone Change with Two versus Four Implants}

Treatment of the edentulous mandible with two or four implants for supporting a full denture is a very controversial subject. Though the German Maxillofacial Surgery Association recommends support on four implants [63], other authors regard two implants as adequate [59,62]. The argument that there is less peri-implant bone resorption with four implants compared with two implants has not yet been adequately proven scientifically.

In the first year following prosthetic treatment there is generally much greater bone resorption than in subsequent years. This typical progression of peri-implant bone loss has already been described in numerous studies and is explained by remodelling, i.e. adaptation of the bony structure to functional loading in the first year following prosthetic treatment. Increased plaque accumulation at the implants, corrosion products of the coating and electrochemical influences are also regarded as being responsible for the comparatively high degree of bone resorption in the first year of functional loading. Measurements of between $0.5 \mathrm{~mm}$ and $1.1 \mathrm{~mm}$ are given in the literature as well as further progression of approx. 0.1 per year in subsequent years [12,23-25].

In the case of two implants rotation of the denture about the bar axis or the axis between the ball attachments may occur during posterior denture loading. The masticatory pressure is mainly transmitted directly to the edentulous alveolar ridge segment. During swallowing, which occurs approximately 2000 times per day, the tongue presses against the lower anterior denture teeth and consequently against the implants. The minimal movement of the implants this produces could induce increased bone resorption due to the non-physiological force transfer to the bone. This is confirmed by the finite element study by Meijer et al., which was able to establish the greatest pressure loading of the bone with two implants connected by a bar [60]. It is questionable, however, to what extent the results obtained from theoretical models and statistical test conditions can be transferred to the clinical conditions with physiological loading.

Several factors must be taken into consideration for each individual patient when deciding whether to place two or four implants. Apart from the general health of the often older patients, consideration must also be given to morphological conditions as well as aesthetic, functional and financial aspects. In addition to the advantage of increased intraoral comfort due to the improved stabilization, which is provided by a more expensive restoration with 4 implants, it is also important to highlight the option of immediate prosthetic restoration. The increased stability of the denture on the mucosa minimizes the risk of pressure spots and reduces the likelihood of food becoming trapped below the denture during food intake [69]. The general functional efficiency of the restoration also remains intact even if one of the implants fails.

\section{Comparison of Bone Changes in Relation to the Opposing Dentition}

The few studies that deal with the influence of the opposing dentition on the peri-implant bone resorption, only investigated patients with fixed dental restorations in the maxilla supported on 
Brånemark implants. The authors, however, obtained different results in this case. While Naert et al. established a statistically significant greater bone resorption with an implant-supported restoration in the opposing jaw compared with a periodontally supported restoration, Eliasson et al. and Carlsson et al. were unable to confirm this observation [54-56].

Apart from the reduced masticatory force of this type of restoration, a possible explanation for the tendency of reduced bone resorption with mucosa-supported full dentures in the opposing jaw may be the occlusal pressure distribution. In implant-supported mandibular full dentures with mucosa-supported full dentures in the maxilla, $70 \%$ of the masticatory force is borne by the dorsal section of the denture and $30 \%$ by the anterior section of the denture. Falk et al. explained that this pressure distribution is due to the increased mobility in the anterior region of the mucosa-supported full denture in the opposing jaw because of the greater resilience of the mucosa in this region [70]. This produces less loading of the osseous structures and implants in the anterior region of the mandible, where the implants are positioned [70-72].

As anticipated, there is also a contrasting loading pattern with a natural dentition as well as implant-supported or periodontalsupported restorations in the opposing jaw. In this situation there is greater masticatory loading in the anterior region than in the dorsal region. The increased pressure loading in the anterior jaw segment and the higher masticatory forces may produce increased bone resorption [70]. The distribution of the occlusal loading in both dentitions, however, depends on the number and distribution of the occlusal contact points. These can also further influence the loading pattern $[70,73]$.

In the only randomized prospective study by Narhi et al. changes in the edentulous maxilla were observed following implant prosthetic treatment in mandible. Significant resorption rates were established in the maxilla regardless of the type of restoration [57].

Other similar observations were made by Elsyad et al. After 4 years of denture-wearing, maxillary the change in the anterior region of the maxilla was significantly higher than the change in the posterior region. Telescopic attachments for implant-retained mandibular overdentures were associated with increased maxillary ridge resorption and flabbiness, and decreased maxillary denture retention when compared to ball attachments [68].

\section{Conclusion}

The edentulous atrophied mandible plays an important role in implantology. It is possible to restore masticatory and phonetic functions by stabilizing the restoration using relatively simple implantology measures. The aim of the present study was to discuss various aspects of this topic, which is also very important economically, using a literature research and possibly derive a recommendation for hybrid prosthetic treatment of the edentulous mandible. This has not yet been adequately investigated scientifically.

Though evaluation of the literature produced a large number of publications with case histories and survival rates, there were only a few prospective randomized clinical that compared different treatment concepts in the edentulous mandible. There were also no significant differences exhibited for peri-implant bone resorption in restorations with two versus four implants. It is therefore currently impossible to provide an evidence-based statement for a specific treatment concept.
Despite all the limitations imposed on the interpretation of the study, the following statements could be made with regard to implantsupported dentures in the edentulous mandible that should be taken into consideration during preoperative consultation with the patient.

In addition to the general health and morphological conditions, individual aspects such as aesthetic, functional and financial factors should also be taken into consideration when deciding whether to place two or four implants.

Two implants represent the easiest, most inexpensive treatment and are adequate for stabilizing a denture in an edentulous mandible. This type of restoration is easy to maintain for the patient with regard to oral hygiene and surgery stress is reduce to a minimum. The disadvantages of this treatment are increased mobility and instability of the denture in the dorsal region.

Apart from increased intraoral comfort, the advantages of treatment using 4 implants include the stable fit of the denture and the option of immediate prosthetic restoration. It is also very important to be able to extend the restoration if an implant fails.

\section{References}

1. Zitzmann NU (2006) Die zahnärztlich-prothetische Versorgung des zahlosen Patienten unter besonderer Berücksichtigung implantatgetragener Rekonstruktionen.

2. Tallgren A (1972) The continuing reduction of the residual alveolar ridge in complete dentures wearers: a mixed-longitudinal study covering 25 years. J Prosthet Dent 27: 120-132.

3. van Waas MA (1983) Ridge resorption in denture wearers after vestibuloplasty and lowering of the floor of the mouth, measured on panoramic radiographs. Dentomaxillofac Radiol 12: 115- 121.

4. Benzing U, Weber H, Simonis A, Engel E (1994) Changes in chewing patterns after implantation in the edentulous mandible. Int J Oral Maxillofac Implants 9: 207-213.

5. van Kampen F, van der Bilt A, Cune M, Bosman F (2002) The influence of various attachment types in mandibular implant-retained overdentures on maximum bite force and EMG. J Dent Res 81: 170-173.

6. Pröbster L, Weber H (1989) Implantatgehaltener Zahnersatz im zahnlosen Unterkiefer in der subjektiven Bewertung des Patienten. Z Zahnärztl Implantol 5:194-197.

7. Boerrigter EM, Stegenga B, Raghoebar GM, Boering G (1995) Patient satisfaction and chewing ability with implant-retained mandibular overdentures: a comparison with new complete dentures with or without preprosthetic surgery. J Oral Maxillofac Surg 53: 1167-1173.

8. Meijer HJ, Raghoebar GM, van't Hof MA, Geertman ME, van Oort RP (1999) Implant-retained mandibular overdentures compared with complete dentures: a 5-years' follow-up study of clinical aspects and patients satisfaction. Clin Oral Implants Res 10: 238-244.

9. Jagger R, Shaikh S, Jagger D (2001) Clinical effectiveness of mandibular implant-retained overdentures. Prim Dent Care 8: 19-24.

10. Behneke N, Tetsch P (1985) Diagnostik und Planung von Implantaten im zahnlosen Unterkiefer. Forschr Zahnärztl Implantol 1: 266-271.

11. Spiekermann H (1987) Implantatprothetik In: Voss R, Meiners H. Fortschritte der zahnärztlichen Prothetik und Werkstoffkunde. Muenchen: Hanser 1987: 279-312.

12. Brånemark PI, Hansson BO, Adell R, Breine U, Lindstrom J, et al. (1977) Osseointegrated implants in the treatment of the edentulous jaw. Experience from a 10-year period. Scand J Plast Reconstr Surg 16: 1-132.

13. Albrektsson T, Dahl E, Enbom L, Engevall S, Engquist B, et al. (1988) Osseointegrated oral implants. A Swedish multicenter study of 8139 consecutively inserted Nobelpharma implants. J Periodontol 59: 287-296. 
14. Adell R, Eriksson B, Lekholm U, Brånemark PI, Jemt T (1990) Long-term follow-up study of osseointegrated implants in the treatment of totally edentulous jaws. Int J Oral Maxillofac Implants 5: 347-359.

15. Babbush CA, Shimura M (1993) Five-year statistical and clinical observations with the IMZ two-stage osteointegrated implant system. Int J Oral Maxillofac Implants 8: 245-253.

16. Nevins M, Langer B (1993) The successful application of osseointegrated implants to the posterior jaw: a long-term retrospective study. Int J Oral Maxillofac Implants 8: 428-432.

17. Block MS, Kent JN (1994) Long-term follow-up on hydroxylapatitecoated cylindrical dental implants: a comparison between developmental and recent periods. J Oral Maxillofac Surg 52: 937-943.

18. Higuchi KW, Folmer T, Kultje C (1995) Implant survival rates in partially edentulous patients: a 3-year prospective multicenter study. J Oral Maxillofac Surg 53: 264-268.

19. Wheeler SL (1996) Eight-year clinical retrospective study of titanium plasma-sprayed and hydroxyapatite-coated cylinder implants. Int J Ora Maxillofac Implants 11: 340-350.

20. Narhi TO, Ettinger RL, Lam EW (1997) Radiographic findings, ridge resorption, and subjective complaints of complete denture patients. Int $J$ Prosthodont 10: 183-189.

21. von Wowern N, Gotfredsen K (2001) Implant-supported overdentures, a prevention of bone loss in edentulous mandibles? Clin Oral Impl Res 12: $19-25$.

22. Kordatzis K, Wright P, Meijer H (2003) Posterior mandibular residual ridge resorption in patients with conventional dentures and implant overdentures. Int J Oral Maxillofac Implants 18: 447-452.

23. Adell R, Lekholm U, Rockler B, Brånemark PI (1981) A 15-year study of osseointegrated implants in the treatment of the edentulous jaw. Int J Oral Surg 10: 387-416.

24. Lindquist LW, Rockler B, Carlsson GE (1988) Bone resorption around fixtures in edentulous patients treated with mandibular fixed tissueintegrated prostheses. J Prosthet Dent 59: 59- 63.

25. Gomez-Roman G, Schulte W, Seiler M, Lutz U, Brehmer A, et al. (1998) Implantation im zahnlosen Unterkiefer. Ergebnisse mit unterschiedlichen Implantatsystemen. Z Zahnärztl Implantol 14: 8-16.

26. Quirynen M, Naert I, van Steenberghe D (1992) Fixture design and overload influence marginal bone loss and fixture success in the Brånemark system. Clin Oral Implants Res 3: 104-111.

27. Schnittman PA, Shulman LB (1979) Recommendations of the consensus development conference on dental implants. J Am Dent Assoc 98: 373-377.

28. Albrektsson T, Zarb G, Worthington P, Eriksson AR (1986) The longterm efficacy of currently used dental implants: a review and proposed criteria of success. Int J Oral Maxillofac Implants 1: 11-25.

29. Jahn M, d'Hoedt B (1992) Zur Definition des Erfolges bei dentalen Implantaten. Ein Vergleich verschiedener Kriterien. Z Zahnärztl Implantol 8: 221-226.

30. Behneke A, Behneke N, d'Hoedt B (2002) A 5-year longitudinal study of clinical effectiveness of ITI solid-screw implants in the treatment of mandibular edentulism. Int J Oral Maxillofac Implants 17: 799-810.

31. Chan MF, Johnston C, Howell RA, Cawood JI (1995) Prosthetic management of the atrophic mandible using endosseous implants and overdentures: a six year review. Br Dent J 179: 329-337.

32. Vajdovich I, Fazekas A (1999) A ten-year clinical follow-up study of prosthetic rehabilitation of the edentulous lower jaw with endosteal dental implants. J Long Term Eff Med Implants 9: 171-183.

33. Bakke M, Holm B, Gotfredsen K (2002) Masticatory function and the patient satisfaction with implant-supported mandibular overdentures: a prospective 5-year study. Int J Prosthodont 15: 575-581.

34. Batenburg RH, Meijer HJ, Raghboer GM, Van Oort RP, Boering G (1998) Mandibular over-dentures supported by two Brånemark, IMZ or ITI implants. A prospective comparative preliminary study: one year results. Clin Oral Implants Res 9: 374-383.
35. Besimo C, Graber G, Schaffner H (1991) Hybrid prosthetic implant supported suprastructures in edentulos mandible. Conus crowns and shell-pin-systems on HA-TI-Implants. 2 prosthetic construction principles. ZWR 100: 70-76.

36. Cune MS, Verhoeven JW, Meijer GJ (2004) A prospective evaluation of Rialoc implants with ball-abutments in the edentulous mandible: 1-year results. Clin Oral Implants Res 15: 167-173.

37. Heckmann SM, Schrott A, Graef F, Wichmann MG, Weber HP (2004) Mandibular two-implant telescopic overdentures. Clin Oral Implants Res 15: 560-569.

38. Makkonen TA, Holmberg S, Niemi I, Olsson C, Tammisalo T, et al. (1997) A 5-year prospective clinical study of Astra Tech dental implants supporting fixed bridges or overdentures in the edentulous mandible. Clin Oral Implants Res 8: 469-475.

39. Meijer HJ, Geertman ME, Raghoebar GM, Kwakman JM (2001) Implantretained mandibular overdentures: 6-year results of a multicenter clinical trial on 3 different implant systems. J Oral Maxillofac Surg 59: 1260-1268.

40. Meijer HJ, Batenburg RH, Raghoebar GM (2001) Influence of patient age on the success rate of dental implants supporting an overdenture in an edentulous mandible: a 3-year prospevtive study. Int J Oral Maxillofac Implants 16: 522-526.

41. Oetterli M, Kiener P, Mericske-Stern R (2001) A longitudinal study of mandibular implants supporting an overdenture: the influence of retention mechanism and anatomic-prosthetic variables on periimplant parameters. Int J Prosthodont 14: 536-542.

42. Romeo E, Chiapasco M, Lazza A, Casentini P, Ghisolfi M, et al. (2002) Implant-retained mandibular overdentures with ITI implants. Clin Oral Implants Res 13: 495-501.

43. Romeo E, Lops D, Margutti E, Ghisolfi M, Chiapasco M, et al. (2004) Long-term survival and sucess of oral implants in the treatment of full and partial arches: a 7-year prospective study with the ITI dental implant system. Int J Oral Maxillofac Implants 19: 147-259.

44. Walton JN, MacEntee MI, Glick N (2002) One-year prosthetic outcomes with implant overdentures: a randomized clinical trial. Int J Oral Maxillofac Implants 17: 391-398.

45. Stoker GT, Wismeijer D (2011) Immediate loading of two implants with a mandibular implant-retained overdenture: a new treatment protocol. Clin Implant Dent Relat Res 13: 255-261.

46. Liao KY, Kan JY, Rungcharassaeng K, Lozada JL, Herford AS, et al. (2010) Immediate loading of two freestanding implants retaining a mandibular overdenture: 1-year pilot prospective study. Int J Oral Maxillofac Implants 25: 784-790.

47. Turkyilmaz I, Tozum TF, Fuhrmann DM, Tumer C (2012) Seven-year follow-up results of TiUnite implants supporting mandibular overdentures: early versus delayed loading. Clin Implant Dent Relat Res 14: 83-90.

48. Krennmair G, Seemann R, Weinländer M, Piehslinger E (2011) Comparison of ball and telescopic crown attachments in implantretained mandibular overdentures: a 5-year prospective study. Int J Oral Maxillofac Implants 26: 598-606.

49. Dashti MH, Atashrazm P, Emadi MI, Mishaeel S, Banava S (2013) The effects of two attachment types on the stresses introduced to the mandibular residual ridge: a 3D finite element analysis. Quintessence Int 44: 585-590.

50. Scepanovic M, Calvo-Guirado JL, Markovic A, Delgardo-Ruiz R, Todorovic A, et al. (2012) A 1-year prospective cohort study on mandibular overdentures retained by mini dental implants. Eur J Oral Implantol 5: 367-379.

51. Eccellente T, Piombino M, Piattelli A, Perrotti V, Iezzi G (2010) A new treatment concept for immediate loading of implants inserted in the edentulous mandible. Quintessence Int 41: 489-495.

52. Heschl A, Payer M, Clar V, Stopper M, Wegscheider W, et al. (2013) Overdentures in the edentulous mandible supported by implants and retained by a Dolder bar: a 5-year prospective study. Clin Implant Dent Relat Res 15: 589-599. 
Citation: Ketabi AR, Bornemann G, Ketabi S, Lauer HC (2014) Hybrid Prosthetic Treatment of the Edentulous Mandible with Two or Four Implants - A Literature Review. Dentistry S2: 007. doi:10.4172/2161-1122.S2-007

Page 8 of 8

53. Frisch E, Ziebolz D, Rinke S (2013) Long-term results of implantsupported overdentures retained by double crowns: a practice-based retrospective study after minimally 10 years follow-up. Clin Oral Implants Res 24: 1281-1287.

54. Naert I, Quirynen M, van Steenberghe D, Darius P (1992) A study of 589 consecutive implants supporting complete fixed prostheses. Part II: Prosthetic aspects. J Prosthet Dent 68: 949-956.

55. Eliasson A, Palmquist S, Svenson B, Sondell K (2000) Five-year result with fixed complete-arch mandibular prostheses supported by 4 implants. Int J Oral Maxillofac Implants 15: 505-510.

56. Carlsson GE, Lindquist LW, Jemt T (2000) Long-term marginal periimplant bone loss in edentulous patients. Int J Prosthodont 13: 295-302.

57. Narhi TO, Geertman ME, Hevinga M, Abdo H, Kalk W (2000) Changes in the edentulous maxilla in persons wearing implant-retained mandibular overdentures. J Prosthet Dent 84: 43-49.

58. Elsyad MA, Khairallah AS, Shawky AF (2013) Changes in the edentulous maxilla with ball and telescopic attachments of implant-retained mandibular overdentures: a 4-year retrospective study. Quintessence Int 44: 487-495.

59. Batenburg RH, Raghboer GM, Van Oort RP, Heijdenrijk K, Boering G (1998) Mandibular overdentures supported by two or four endosteal implants. A prospective, comparative study. Int J Oral Maxillofac Surg 27: 435-439.

60. Meijer HJ, Starmans FJ, Stehen WH, Bosman F (1994) A threedimensional finite element study on two versus four implants in an edentulous mandible. Int J Prosthodont 7: 271-279.

61. Visser A, Raghoebar GM, Meijer HJ, Batenburg RH, Vissink A (2005) Mandibular overdentures supported by two or four endosseous implants. A 5-year prospective study. Clin Oral Implants Res 16: 19-25.

62. Wismeijer D, van Waas MA, Mulder J, Vermeeren JI, Kalk W (1999) Clinical and radiological results of patients treated with three treatment modalities for overdentures on implants of the ITI dental implant system. A randomized controlled clinical trial. Clin Oral Implants Res 10: 297-306.
63. DGZMK Stellungnahme der DGZMK (2005) Implantologie in der Zahnheilkunde.

64. Adell R, Lekholm U, Rockler B, Brånemark PI, Lindhe J, et al. (1986) Marginal tissue reactions at osseointegrated titanium fixtures (I). A 3 year longitudinal prospective study. In Oral Maxillofac Surg 15: 39-52.

65. Mombelli A, Mericske Stern R (1990) Microbiological features of stable osseointegrated implants used as abutments for overdentures. Clin Oral Implants Res 1: 1-7.

66. Rosenberg ES, Torosian JP, Slots J (1991) Microbial differences in 2 clinically distinct types of failures of osseointegrated implants. Clin Oral Implants Res 2: 135-144.

67. Lang NP, Bragger U, Walther D, Beamer B, Kornman KS (1993) Ligature-induced peri-implant infection in cynomolgus monkeys. I. Clinical and radiographic findings. Clin Oral Implants Res 4: 2-11.

68. Isidor F (1996) Loss of osseointegration caused by occlusal load of oral implants. A clinical and radiographic study in monkeys. Clin Oral Implants Res 7: 143-152.

69. Falk H, Laurell L, Lundgren D (1989) Occlusal force pattern in dentitions with mandibular implant-supported fixed cantilever prostheses occluded with complete dentures. Int J Oral Maxillofac Implants 4: 55-62.

70. Raghoebar G, Meijer H, Terheyden H, Vissink A (2004) Evidenzbasiertes Behandlungskonzept für die Versorgung des atrophierten Unterkiefers mit implantatgestützten Deckprothesen. Implantologie 12: 361-372.

71. Lundgren D, Laurell L (1986) Occlusal force pattern during chewing and biting in dentitions restored with fixed bridges off cross-arch extension. J Oral Rehabil 13: 57-71

72. Falk H, Laurell L, Lundgren D (1990) Occlusal interferences and cantilever joint stress in implant-supported prostheses occluding with complete dentures. Int J Oral Maxillofac Implants 5: 70-77.

73. Laurell L, Lundgren D (1988) Distribution of occlusal forces along unilateral posterior two-unit cantilever segments in cross-arch fixed partial dentures. J Prosthet Dent 60: 106-112.
This article was originally published in a special issue, entitled: "Chornic Orofacial Pain or Temporomandibular Disorders", Edited by Dr. Francisco Alencar Jr., Marquette University, USA 